\title{
Analysing the determinants of Italian university student mobility pathways
}

\author{
Silvia Columbu ${ }^{1 *}$ (D) Mariano Porcu², Ilaria Primerano ${ }^{3}$, Isabella Sulis ${ }^{2}$ and Maria Prosperina Vitale ${ }^{3}$
}

\section{${ }^{*}$ Correspondence:}

silvia.columbu@unica.it

${ }^{1}$ Department

of Mathematics

and Computer Sciences,

University of Cagliari, via

Ospedale 72, 09123 Cagliari, Italy

Full list of author information is available at the end of the article

\begin{abstract}
In this paper, we study the mobility choices of Italian students in their transition from a bachelor's to a master's degree level with an added emphasis on their overall mobility pathways. We consider individual data from the Italian National Student Archive on two cohorts of students who were enrolled in the academic years 2011-2012 and 2014-2015. We followed both cohorts in Italian universities for six academic years. This allowed us to depict five different profiles of students, categorise them as stayers vs. movers, and work at two different levels. Logit models were then adopted to study the probability to be in mobility at a master's level, given that a student had been a stayer at bachelor's degree, and to assess the effect of the field of study. Apart from individual characteristics, network centrality measures were encompassed in the model to assess the university attractiveness in influencing mobility choices.
\end{abstract}

Keywords: Mobility choices, Social network analysis, Hub and authority measures, Logit models, Disciplinary fields

\section{Introduction}

In this paper, we aim to study the mobility choices of Italian students in their transition from bachelor's to master's degree programmes with an added emphasis on their overall mobility pathways as conditioned by the choice of the field of study. We consider individual data from the Italian National Student Archive on two cohorts of students enrolled in the academic years 2011-2012 and 2014-2015. We followed both cohorts in Italian universities for six academic years. On the basis of the categorisation regarding the overall mobility pathways advanced by Sulis et al. (2019), the present contribution focuses on student mobility by employing descriptive analysis to depict student profiles in terms of their whole mobility pathways, i.e., stayers vs. movers, in the transition from a bachelor's to a master's degree. We adopt logit models to explain the determinants of being a mover at a master's degree, given that the student was a stayer at a bachelor's degree, taking into account differences in personal characteristics and in the choices of the field of study. Special attention is also devoted to the description of student mobility choices at different stages of his or her university career according to different disciplinary fields and the location of the university. priate credit to the original author(s) and the source, provide a link to the Creative Commons licence, and indicate if changes were made. The images or other third party material in this article are included in the article's Creative Commons licence, unless indicated otherwise in a credit line to the material. If material is not included in the article's Creative Commons licence and your intended use is not permitted by statutory regulation or exceeds the permitted use, you will need to obtain permission directly from the copyright holder. To view a copy of this licence, visit http://creativecommons.org/licenses/by/4.0/. 
Given its nature, university mobility can be modelled as a network by observing the flows of students from the place where they achieved their bachelor's degree, i.e., origin, to the place where they enrolled in their master's degree, i.e., destination. Network measures are used to obtain information on the position of each university in the outgoing and incoming students' exchange processes based on hub and authority scores (Kleinberg, 1999). These two centrality measures have been adopted as predictors in the regression setting, as they mainly provide information on university attractiveness for explaining the second level mobility choices of students (Columbu et al., 2021). More specifically, the hub scores can be used as proxies of the awareness of student mobility choices, as they consider the flows of students moving towards a good authority university. The authority scores, in turn, can be treated as proxies of the prestige of a university, as they measure the degree to which the university is able to attract students from multiple hubs.

The factors that affect student mobility are considered in a logistic regression model, which is addressed to disentangle the effect of university centrality measures as an indirect indicator of university prestige and the degree of information regarding the reputation of an academic institution in the student exchange process. In particular, once mobility profiles and network centrality measures have been defined, we focus on the change of the mobility status from a bachelor's to a master's degree. Logit models are thus estimated to assess the effects of personal characteristics and disciplinary fields on students' probability of being in mobility at a master's degree level. University centrality measures-introduced as predictors in the regression model-allow us to further assess the role played by the position of each university in the network mobility structure in determining the propensity of its students to undertake a mobility decision. Moreover, in this methodological context, we address the following three research questions:

1. What are the characteristics of students who experienced different mobility pathways?

2. What are the effects of disciplinary fields on student mobility choices?

3. How does university centrality, in terms of hub and authority scores, influence the mobility choices of students?

The remaining of this paper is structured as follows. A brief theoretical background is presented in "Theoretical background". The data are described in "Data". "Network data definition" is devoted to the definition of student mobility networks with a focus on visualisation tools to highlight significant links and student flows among geographical macro-areas. Here, network measures are computed to underpin the centrality of universities in this process. Results of the logit model are presented and discussed in "Modelling approach". Finally, concluding remarks are given in "Conclusions".

\section{Theoretical background}

Several factors, including financial aspects and cultural barriers, play a pivotal role in student mobility decisions (Donnelly and Gamsu, 2018). Authors exploring the motivation behind student mobility in higher education mainly focus on depicting the geographical shape of migration flows by addressing the analyses to capture differences 
across universities and territorial areas, and to assess the main determinants which seem to drive important student decisions. The most recent literature on mobility in United Kingdom argues that the main motivation behind the decision to select a non-local university is a better future return in terms of job opportunities, i.e., human capital perspective, as well as the environment also in terms of facilities and services offered by the cities hosting university students, i.e., consumption perspective (Sanchez Barrioluengo and Flisi, 2017). Thus, the factors that affect student mobility are related to the home territorial entities (push factors) and to the hosting country amenities (pull factors) with respect to other potential destinations which supply tertiary education. In this perspective, in the British framework, Donnelly and Gamsu (2018) detect six different types of students in mobility, further distinguishing between commuter students, who are still living with their family, and movers, who have left their family home. Within these groups, distance is being used as gradient to differentiate between short, medium and long travel categories. Their findings suggest that the migration type is strongly associated with the social class group, the ethnic group and the geographic location.

Moving on student domestic migration, the Italian university system is characterised by a well-known north-south divide, which in turn features an unbalanced flow of students that each year migrate to the northern regions of the country for university studies (Bacci and Bertaccini, 2021; Enea, 2018; Pitzalis and Porcu, 2015; Rizzi et al., 2021). This phenomenon has been largely studied in the last years, since it is strictly connected to several socioeconomic and demographic issues that have contributed to large disparities between different geographical areas in the country (Giambona et al., 2017). The more vulnerable territorial areas are characterised by lower transition rates from high school to university, lower graduation rates and higher probability for students to migrate in search of job opportunities (Ballarino and Panichella, 2021; Dotti et al., 2013, 2014; Istat, 2018; Vittorietti et al., 2019). These factors have contributed to a drain in the endowment of human capital in these areas with a well-known serious effect on the development and growth of these territories (Becker, 1964; Fratesi and Percoco, 2014; Schultz, 1971).

According to the AlmaLaurea survey 2020 on graduates employment conditions at 1 , 3 and 5 years from graduation ${ }^{1}$, approximately $54 \%$ of master's degree graduates were employed in north-east and north-west areas within 1 year of graduation. The rate is just slightly lower, i.e., $50.5 \%$, after 5 years. Moreover, the percentage of graduates who were employed in the southern area of the country ranges between $18.6 \%$ and $21.0 \%$. These rates do not match with the distribution of students enrolled in a master's degree according to their residence area, provided by the Italian Ministry of University and Research (MUR). ${ }^{2}$

As part of this, many studies in the last decade have also analysed student mobility choices at a bachelor's level (D'Agostino et al., 2019; Enea, 2018; Giambona et al., 2017; Pitzalis and Porcu, 2015; Rizzi et al., 2021), defining the transition from a high school to a university as a crucial step in determining future migration choices. It is well-known that students who undertake a university programme in another region rarely come back

\footnotetext{
${ }^{1}$ www.almalaurea.it

2 The percentage of those students who reside in the south and are enrolled in a master's degree programme for the 2011 and 2014 cohorts varies between $34 \%$ and $36 \%$
} 
to their residence area for further studies or look for a job after graduation there. Thus, in this perspective, student mobility choices can be considered anticipatory of migrations which have largely considered the less developed areas of the country, since the second half of the 20th century (Ballarino and Panichella, 2021; Dotti et al., 2014; Mencarini, 1996.

To the best of our knowledge, if we consider the internal migration of students in the transition from the first (bachelor) to the second (master) university level, the literature is quite limited. For instance, Enea (2018) describes the internal flow from the south to the north of Italy, and in a recent contribution Primerano et al. (2021) is proposed a multiplex network approach to study mobility choices of Italian students according to the field of study. An international perspective is discussed in the contribution of VanMol et al. (2020) that describes the effect of student mobility in the early Dutch labour market by considering the different experiences held at bachelor's or master's levels.

This paper hereby provides new insights into our understanding of student mobility. First, it explores in a comparative perspective the characteristics of students who experience different mobility pathways in their overall university experience. Second, it assesses the determinants of choosing a non-local university in the transition from a bachelor's to a master's degree, considering the effect of belonging to different disciplinary fields. Third, it investigates the role played by each university in the student mobility network.

\section{Data}

We employ data at individual level ${ }^{3}$ from the National Student Registry Office (ANS) of the MUR to analyse student mobility choices. The analysis focuses on two cohorts of students enrolled in bachelor's degrees in the a.y. 2011-2012 and 2014-2015 with the main purpose of studying the transition from a bachelor's to a master's degree, and the characteristics of incoming and outgoing student flows from each university. The use of data from two different cohorts allows us to capture eventual differences of this phenomenon over specific time frames. More specifically, only the subsets of students of the two cohorts that achieved a bachelor's degree and enrolled in a master's degree are investigated and followed up for 6 years. Students from medical degrees and coming from a foreign secondary school are excluded from our analysis.

Students have been classified as movers if they have enrolled in a region different from their region of first residence and if the degree programme chosen (either at bachelor's or master's degree levels) is located in a municipality of at least 90 min of traveling from their city of origin, following the definition provided in Columbu et al. (2021), otherwise they have been classified as stayers (Attanasio and Enea, 2019). In this way, we avoid classifying as movers those students who change region for reaching the university yet selecting a close or local university. The threshold value of 90 min has been defined by looking at the distribution of the travel distances and by adopting the criterion that it is unlikely for students to commute for more than $3 \mathrm{~h}$ from their residence city to reach

\footnotetext{
${ }^{3}$ Note that the micro-data at student level are available from the ANS archive only for those universities that are involved in the Italian Ministerial grant PRIN 2017 CUP: B78D19000180001. The data analysed are derived from the MOBYSU.IT database.
} 
Table 1 Student mobility profiles

\begin{tabular}{lll}
\hline Bachelor's Degree: mobility status & Master's Degree: mobility status & \\
\hline & Stayer II & Mover II \\
Stayer I & Stayer I \& Stayer II & Stayer I \& Mover II \\
Mover I & Mover I \& Stayer II & Mover I \& Mover I| \\
\hline
\end{tabular}

university sites. Therefore, the rule followed to define mover students should ensure that we exclude commuters and we classify as movers those students that move to live to another city during their university studies.

Students are grouped into the category of movers at a bachelor's degree level (Mover I), and movers at master's degree level (Mover II). The same procedure has been applied to identify stayers at both stages, defining students as stayers at a bachelor's level (Stayer I) and at a master's level (Stayer II). The combination of these two conditions of mobility status at both levels gives rise to four student profiles in terms of mobility in their overall career paths (Table 1).

Moreover, to consider that mover students can modify their mobility choices between the first and the second levels, we differentiate between Mover II who enrolled in a master's degree in the same region, where they graduated at the first level and mover students who moved in another region in the transition from a bachelor's to a master's degree. This second classification provides some information on the importance of the first choice in conditioning second-level mobility. On the basis of these specific definitions and by observing the joint student mobility status at the two levels of university studies, five different profiles have been depicted which describe the overall mobility pathway:

1. Stayer I \& Stayer II: students who have been classified as stayers at both levels;

2. Mover I \& Stayer II: students who were in mobility at a bachelor's level and enrolled in a local university at a master's level. This profile allows to identify those students who changed their status from mover to stayer in the transition from a bachelor's to a master's level;

3. Stayer I \& Mover II: students who are enrolled in a local university for the bachelor and undertake the decision to move to a university outside their region of residence for attending master's level studies. This profile allows to identify those students who changed their status from stayer to mover in the transition from a bachelor's to a master's level;

4. Mover I \& II in the same region-SR: students who keep their mover status at both levels and do not change the region, where the university is located in the transition from a bachelor's to a master's level;

5. Mover I \& II in different regions-DR: students who keep their mover status at both levels and make a second mobility choice in the transition from a bachelor's to a master's level.

The above-defined five profiles include all possible mobility pathways that students can experience during their university careers. The distribution of students according to 
Table 2 Distribution of students in the two cohorts according to key characteristics (row \%)

\begin{tabular}{|c|c|c|c|c|c|c|}
\hline Variables & Stayer I \& II & $\begin{array}{l}\text { Mover I } \\
\text { \& Stayer } \\
\text { II }\end{array}$ & $\begin{array}{l}\text { Stayer I \& } \\
\text { Mover II }\end{array}$ & Mover I \& II-SR & Mover I \& II-DR & $N$ \\
\hline \multicolumn{7}{|c|}{ Macro-area res. cohort 2011* } \\
\hline Centre & 77.8 & 0.8 & 11.8 & 7.8 & 1.6 & 14,130 \\
\hline Islands & 48.8 & 0.7 & 26.2 & 19.4 & 4.9 & 6022 \\
\hline North & 85.5 & 0.9 & 7.8 & 4.9 & 0.9 & 29,564 \\
\hline South & 55.4 & 0.9 & 15.7 & 22.4 & 5.5 & 18,470 \\
\hline \multicolumn{7}{|l|}{ Gender } \\
\hline Female & 72.2 & 1.1 & 12.7 & 11.2 & 2.9 & 38,467 \\
\hline Male & 73.0 & 0.6 & 12.0 & 12.0 & 2.4 & 29,719 \\
\hline \multicolumn{7}{|l|}{ High school } \\
\hline LYCEUM Hum & 64.3 & 1.0 & 15.6 & 15.5 & 3.6 & 11,486 \\
\hline LYCEUM Scient. & 72.4 & 0.8 & 12.4 & 12.0 & 2.5 & 34,071 \\
\hline Other & 76.9 & 1.0 & 10.8 & 8.9 & 2.4 & 22,629 \\
\hline \multicolumn{7}{|c|}{ Scient. macro-area 1st } \\
\hline Scientific & 75.0 & 0.6 & 10.8 & 11.4 & 2.1 & 27,754 \\
\hline Social & 69.8 & 1.0 & 13.7 & 12.5 & 3.0 & 26,514 \\
\hline Humanistic & 72.7 & 1.1 & 13.2 & 9.9 & 3.1 & 13,918 \\
\hline \multicolumn{7}{|c|}{ Scient. macro-area 2nd } \\
\hline Scientific & 75.0 & 0.6 & 10.7 & 11.6 & 2.1 & 27,171 \\
\hline Social & 70.4 & 1.1 & 13.5 & 11.9 & 3.2 & 30,371 \\
\hline Humanistic & 72.3 & 1.0 & 13.6 & 10.4 & 2.7 & 10,644 \\
\hline Total (\%) & 72.5 & 0.9 & 12.4 & 11.5 & 2.7 & 68,186 \\
\hline Total $^{\#}$ & 49447 & 603 & 8454 & 7873 & 1809 & 68,186 \\
\hline \multicolumn{7}{|l|}{ High school grade } \\
\hline Mean & 82.2 & 80.9 & 82.8 & 85.7 & 82.7 & \\
\hline SD & 11.7 & 11.3 & 11.5 & 11.7 & 11.4 & \\
\hline \multicolumn{7}{|c|}{ Bachelor's degree grade } \\
\hline Mean & 100.3 & 99.6 & 102.1 & 99.7 & 100.0 & \\
\hline SD & 7.8 & 8.4 & 7.2 & 8.3 & 7.9 & \\
\hline \multicolumn{7}{|c|}{ Macro-area res. cohort 2014* } \\
\hline Centre & 73.2 & 1.1 & 14.3 & 9.4 & 2.0 & 13,391 \\
\hline Islands & 46.4 & 0.8 & 24.4 & 23.0 & 5.4 & 5755 \\
\hline North & 83.6 & 1.2 & 8.4 & 5.6 & 1.2 & 29,775 \\
\hline South & 52.6 & 0.8 & 17.7 & 22.5 & 6.5 & 16,239 \\
\hline \multicolumn{7}{|l|}{ Gender } \\
\hline Female & 69.8 & 1.3 & 13.7 & 11.7 & 3.5 & 36,563 \\
\hline Male & 71.3 & 0.7 & 12.9 & 12.6 & 2.5 & 28,597 \\
\hline \multicolumn{7}{|l|}{ High school } \\
\hline LYCEUM Hum & 61.4 & 1.3 & 15.7 & 17.0 & 4.5 & 10,335 \\
\hline LYCEUM Scient & 69.6 & 0.8 & 13.4 & 13.3 & 2.9 & 31,451 \\
\hline Other & 75.6 & 1.2 & 12.2 & 8.3 & 2.6 & 23,374 \\
\hline \multicolumn{7}{|c|}{ Scient. macro-area 1st } \\
\hline Scientific & 72.9 & 0.6 & 11.9 & 12.4 & 2.2 & 26,430 \\
\hline Social & 67.8 & 1.2 & 14.6 & 12.7 & 3.7 & 24,653 \\
\hline Humanistic & 70.5 & 1.4 & 13.9 & 10.6 & 3.6 & 14,077 \\
\hline \multicolumn{7}{|c|}{ Scient. macro-area 2nd } \\
\hline Scientific & 72.9 & 0.6 & 11.9 & 12.4 & 2.2 & 25,870 \\
\hline Social & 68.5 & 1.3 & 14.4 & 12.1 & 3.8 & 28,994 \\
\hline Humanistic & 69.9 & 1.3 & 14.2 & 11.3 & 3.3 & 10,296 \\
\hline
\end{tabular}


Table 2 (continued)

\begin{tabular}{|c|c|c|c|c|c|c|}
\hline Variables & Stayer I \& II & $\begin{array}{l}\text { Mover I } \\
\text { \& Stayer } \\
\text { II }\end{array}$ & $\begin{array}{l}\text { Stayer I \& } \\
\text { Mover II }\end{array}$ & Mover I \& II-SR & Mover I \& II-DR & $N$ \\
\hline Total (\%) & 70.5 & 1.0 & 13.3 & 12.1 & 3.1 & 100.0 \\
\hline Total \# & 45,920 & 662 & 8693 & 7891 & 1994 & 65,160 \\
\hline \multicolumn{7}{|c|}{ High school grade } \\
\hline Mean & 82.9 & 82.1 & 83.6 & 86.9 & 84.2 & \\
\hline SD & 11.3 & 11.1 & 11.0 & 11.2 & 11.2 & \\
\hline \multicolumn{7}{|c|}{ Bachelor's degree grade } \\
\hline Mean & 101.6 & 101.3 & 103.4 & 101.6 & 101.8 & \\
\hline SD & 7.5 & 7.7 & 6.7 & 7.7 & 7.3 & \\
\hline
\end{tabular}

these five profiles is listed in Table 2. Overall, we followed the mobility choices of 68,168 students belonging to the 2011-12 cohort and 65,160 belonging to the 2014-15 cohort. In both cohorts we have selected those students who had concluded their bachelor's degree studies on time, or with a maximum of 2-year delay, and have enrolled in a master's degree programme within 6 years from their first enrolment at university.

The overall rate of movers at the second level varies from $26.6 \%$ of the 2011-12 cohort to $28.5 \%$ of the $2014-15$ cohort. A comparison between the two cohorts shows that the percentage of students who did not have mobility experiences during the two levels reduced approximately $2 \%$, whereas the rate of Stayer I \& Mover II increased about $1 \%$. Table 2 clearly shows marked differences in the five profiles according to the geographical macro-areas of residence (origin), the type of high school and the scientific macro-area of the degree programme at bachelor's (first) and master's (second) levels. The results indicate that the rate in the category Stayer I \& II varies between $46.4 \%$ and $48.8 \%$ in the islands, between $52.6 \%$ and $55.4 \%$ in the south, between $73.2 \%$ and $77.8 \%$ in the Center, and between $83.6 \%$ and $85.5 \%$ in the North. In the before mentioned four geographical macro-areas, the rates have been decreasing between the two cohorts, pointing at an ascending trend in the propensity to be in mobility and the heterogeneity between different macro-geographical areas. The probability to be in the category Stayer I \& Mover II is the highest for students who reside in southern Italy and involves approximately $25 \%$ of students from the islands. The differences in the probability of belonging to the categories of Mover I \& II are also remarkable among geographical macro-areas, with data that confirm again a higher propensity of students coming from the southern areas of the country to be in this profile more than others, and with a trend that increases between these two cohorts. Another aspect worth mentioning is that the rate of students in mobility at both grades who changed region, and thus also university, in the transition from a bachelor's to a master's level is remarkably higher for students residing in the southern regions than for students from the north (approximately $5 \%$ in 2014-15 cohort).

Regarding individual socio-demographic characteristics and high school information, there are slight differences between the two groups of males and females in the probability of belonging to the five profiles with an advantage of females in the categories 
which denote mobility choices. The high school attended, in turn, seems to be clearly associated with a different propensity to be in mobility. In particular, students from a lyceum ${ }^{4}$ in the field of humanistic studies choose less frequently to attend a local university for their entire university career path (64.3\%), followed by those from a lyceum in the field of scientific studies (72.4\%). Both of these traditional lyceum pathways have higher rates of students in mobility in comparison to those students who come from other types of secondary school. Namely, the percentage of those who were in mobility for their entire university pathway varies in the intervals: $19.1-21.5 \%$ for students from the humanistic lyceum, 14.5-16.2\% for students from scientific lyceum and 10.9-11.3\% for students from other secondary schools. Considering the secondary school grade, students in the category Mover I \& II (SR) have an average grade of about 3.5 points greater than students who were not involved in mobility experiences, whereas a high propensity to move for the first time for master's studies is associated with higher bachelor's degree grades. The distribution of students, according to the macro-scientific areas at bachelor's and master's degree and their mobility profiles, highlights that the category of Stayer I \& Mover II shows some divergences across different subjects, with a greater propensity of the social and humanistic areas to be in mobility at the second level.

Considering the choice of the degree programme at a master's level, students have been clustered into 10 main disciplinary fields with a similar end-vocation: agriculture, forestry, fisheries and veterinary sciences; arts and humanities; business, administration and law; education; engineering, manufacturing and construction; health and welfare; information and communication technology; natural sciences, mathematics and statistics; services; social sciences, journalism and information. This classification allows us to better shape divergences across different disciplinary fields within the four distinct disciplinary macro-areas considered in Table $2 .^{5}$ Indeed, it is intriguing to highlight the heterogeneity between the disciplinary fields in the probability to be Stayer I \& II and Stayer I \& Mover II. The rate of students who did not have any kind of mobility experience varies, conditional upon the field of study, between $65.7 \%$ and $81.2 \%$ in the $2011-12$ cohort and between $64.6 \%$ and $82.0 \%$ in the $2014-15$ cohort. The highest rates of movers since completing a bachelor's degree are registered in social sciences, journalism and information and business, administration and law. The highest propensities to be in mobility at the second level, in turn, are registered in social sciences, journalism and information. Moreover, the decision to drop out from a local university in the transition from a bachelor's to a master's level degree is strongly associated with the choice of a specific disciplinary field, as it is shown by the variability between them in the probability to be Stayer I \& Mover II.

In the following sections, we aim to shade some light into the determinants of student mobility profiles considering the whole university experience of students, and the role played by universities in terms of hub and authority centrality measures in sending and attracting a large number of students.

\footnotetext{
${ }^{4}$ The lyceum provides upper secondary level education which is aimed for preaparation for further tertiary-level studies.

${ }^{5}$ A Table of descriptive statistics is available upon request.
} 
By focusing on the subgroup of students who had no mobility experience at a bachelor's level (Profile 1 and 3), the analysis focuses on the choices of those who changed their mobility status from stayer to mover in the transition from a bachelor's to a master's degree. For these research aims, in the explanatory approach, we have modelled the probability to be Stayer I \& Mover II instead of Stayer I \& II using a logistic regression model, which also includes network measures as predictors.

\section{Network data definition}

Given their nature, student mobility flows can be modelled as a network. Different approaches have been introduced in the related literature to exploit this phenomenon in the framework of network analysis perspective. Here, geographical units could be considered as sets of nodes in unipartite (Restaino et al., 2020; Santelli et al., 2019), bipartite or tripartite (Genova et al., 2019; Vitale et al., 2020) network structures.

For the purpose of our research frame, unipartite networks are considered by defining weighted and directed networks for the two cohorts under analysis, in which nodes represent universities and links account for a mobility flow from the university, where the student gained the bachelor's degree (origin) to the university of enrolment in the master's degree (destination). Link weights stand for the size of the mobility flow in terms of number of movers among pairs of universities.

The method proposed by Genova et al. (2019) is applied for only the purpose of network visualisation, with the aim to transform the observed network to its skeleton by removing links that appear less important. ${ }^{6}$ In Fig. 1, the derived networks of Italian universities are shown for the 2011-12 and 2014-15 student cohorts in which the node's size is proportional to the in-degree centrality index, showing the universities with the highest number of incoming students. The link's weight is proportional to the number of students moving among pairs of universities. The aggregation of universities according to the four geographical macro-areas is highlighted using node colour and by plotting the four groups into rectangular boxes.

Looking at each geographical macro-area in the two network configurations, the student flow from the bachelor's to the master's level is mainly nested into regional borders. Movers tend to enrol in a university located in the same geographical macro-area, where they have gained their bachelor's degrees. The mobility also seems to be concentrated among internal universities located within the region in the case of Campania (UNINA, UNIPARTHENOPE, UNIOR and UNISOB in Naples and UNISA in Salerno), Lazio (UNIROMA1 and UNIROMA3), Emilia Romagna (UNIBO and UNIMORE), Veneto (UNIPD and UNIVE), and Lombardy (UNIBG, UNIPV towards UNIMIB, UNICATT and UNIMI). Some exchanges connecting different regions are located both in the same geographical macro-area between the University of Genova (UNIGE) and the Politecnico of Milan (POLIMI), University of Parma (UNIPR) and Cattolica University of Milan (UNICATT) as well as in different geographical macro-areas, such as the Universities of Florence (UNIFI) and Bologna (UNIBO). These findings confirm that the most relevant

\footnotetext{
${ }^{6}$ A directed link from the origin to the destination remains in the graph only if it is statistically significant with respect to a null hypothesis based on random graph configuration. The extraction of these links is made by setting the threshold of $p$-value according to the Bonferroni correction with $\alpha=0.05$.
} 


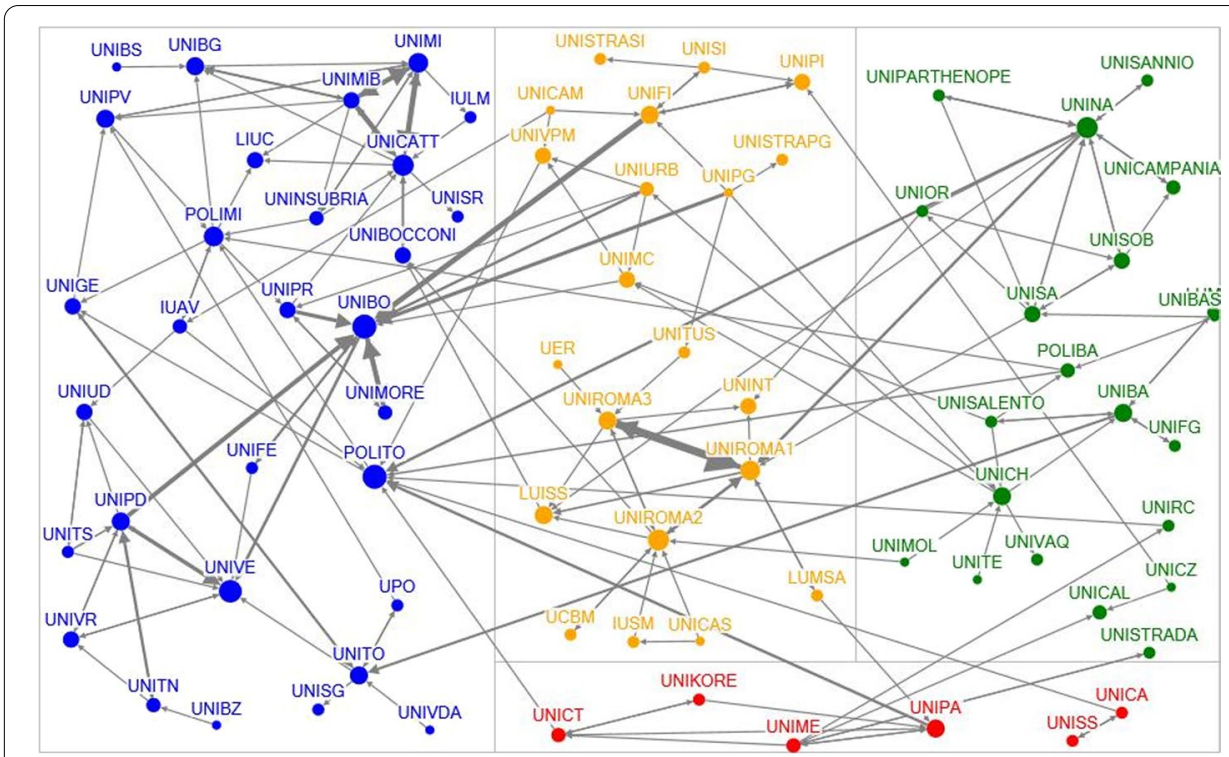

(a) 2011

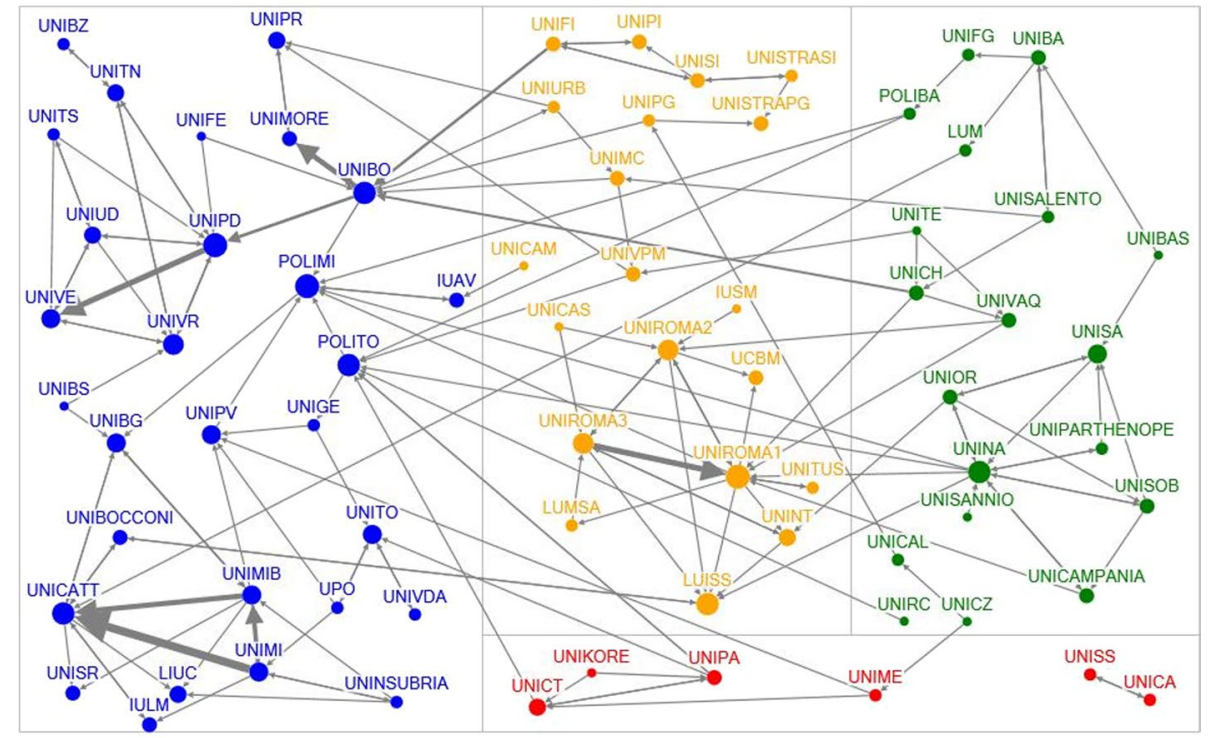

(b) 2014

Fig. 1 Network visualisation at university level for 2011-12 and 2014-15 student cohorts. Node's colour are related to geographical macro-areas: blue $=$ north, orange $=$ centre, green $=$ south and red $=$ islands; node's size represent the university in-degree centrality index and link's weight is proportional to the number of students moving among pairs of universities

student mobility trajectories take place from the south of Italy to the centre and north of the country, i.e., from the University of Naples Federico II (UNINA) to La Sapienza University of Rome (UNIROMA1) and for this latter to the Politecnico of Milan (POLIMI), from the universities of Bari (UNIBA), Catania (UNICT) and Palermo (UNIPA) to the Politecnico of Turin (POLITO).

To sum up, the role played by universities emerges looking at incoming and outgoing students in the two network configurations. The Universities of Naples Federico II, 


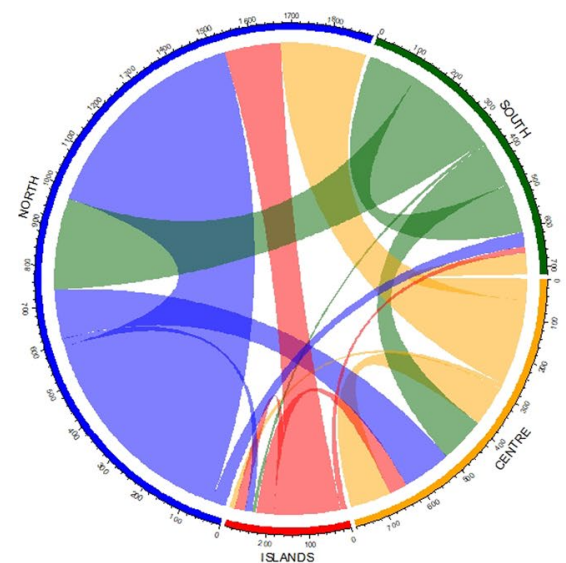

(a) Whole Network

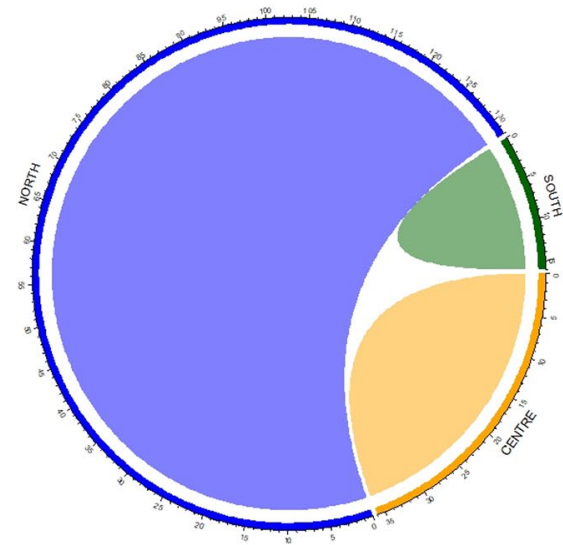

(c) Mover I \& II same region

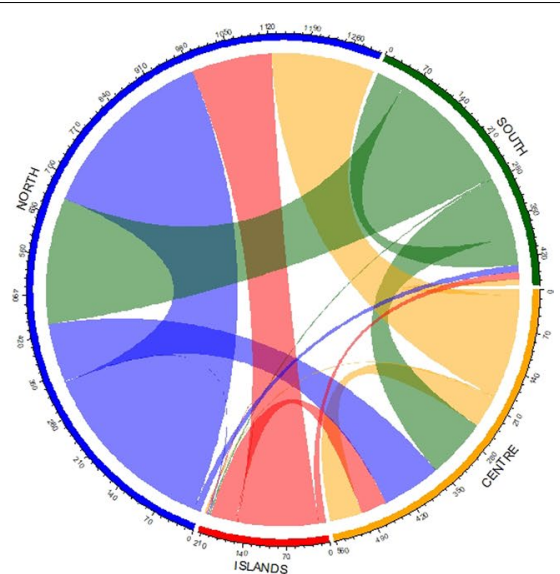

(b) Stayer I \& Mover II

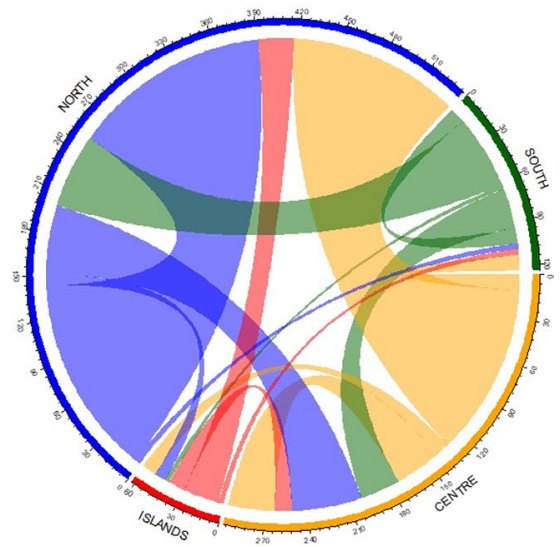

(d) Mover I \& II different region

Fig. 2 Chord diagrams of overall student mobility and networks derived from the student profiles of the 2011-12 cohort according to Italian macro-areas (blue = north, orange $=$ centre, green $=$ south and red $=$ islands)

Palermo, Bari, and Florence show a high rate of outgoing students towards universities outside the geographical boundaries, while the Universities of Milan and Bologna show a high number of incoming students. The Universities of Rome and Turin, in turn, are characterised by both of these processes.

By considering the student mobility profiles (movers vs. stayers) described in "Data", Figs. 2 and 3 display the overall student mobility and networks derived from the profiles of Stayer I \& Mover II, Mover I \& II-SR, Mover I \& II-DR ${ }^{7}$ for the two student cohorts, respectively. Each geographical macro-area is represented through a fragment

\footnotetext{
7 Since the interest is in highlighting student mobility among universities located in different macro-areas, the flows of students between universities located in the same province are disregarded, by removing the within universities student exchanges hold on the main diagonal of the network matrices. This expedient allows to manage the attraction effect and the size effect of some universities, due to the extension of geographical borders and the density of the population living there, as well as to the presence of one or more prestigious universities.
} 


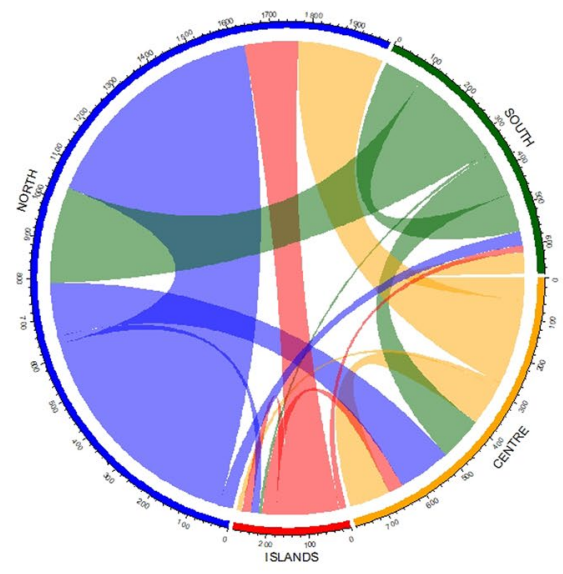

(a) Whole Network

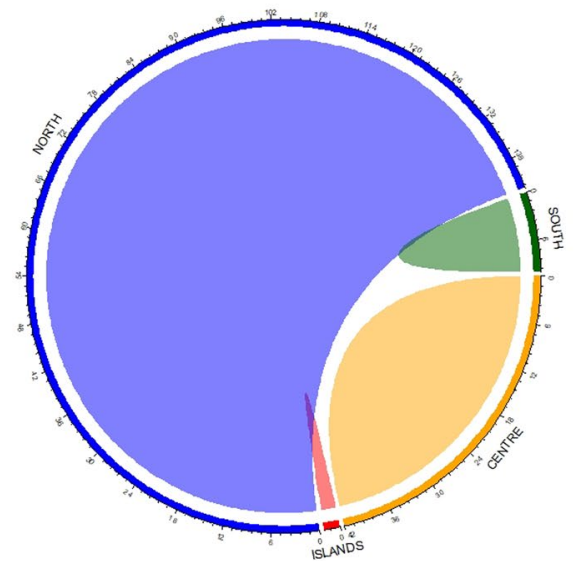

(c) Mover I \& II same region

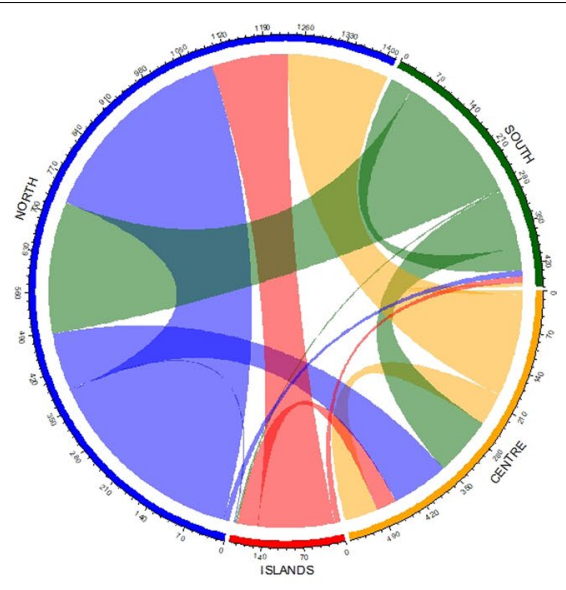

(b) Stayer I \& Mover II

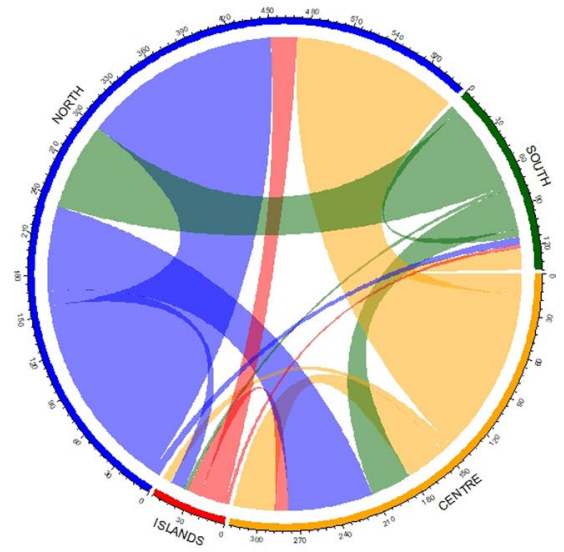

(d) Mover I \& II different region

Fig. 3 Chord diagrams of overall student mobility and networks derived from the profiles of the 2014-15 cohort according to Italian macro-areas (blue $=$ north, orange $=$ centre, green $=$ south and red $=$ islands)

of the circle with a different colour, then a link is drawn from one fragment to another one when dealing with external links among geographical macro-areas, otherwise the link points to the same starting fragment showing internal links.

Student flows occur within the same geographical macro-area: students who choose to change university when enrolling in the master's degree mainly move between regions within the same macro-area, where they obtained the bachelor's degree. For the profile Mover I \& II-SR ${ }^{8}$ the student mobility is by definition concentrated within the geographical macro-area they belong to; while for Mover I and II-DR, the visualisation allows to emphasise the exchanges among geographical areas.

\footnotetext{
${ }^{8}$ For the 2011-12 cohort, the islands' fragment is not shown in this diagram since all the student exchange occurs only between the same provinces.
} 
Table 3 Top 10 hub and authority scores at university level for the 2011-12 and 2014-15 student cohorts

\begin{tabular}{lcccr}
\hline & Hub 2011 & Authority 2011 & Hub 2014 & Authority 2014 \\
\hline 1 & UNIBO (1.000) & UNIBO (1.000) & UNIBO (1.000) & UNIBO (1.000) \\
2 & UNIBA (0.800) & UNITO (0.543) & UNIMI (0.851) & UNICATT (0.823) \\
3 & UNIFI (0.786) & UNICATT (0.468) & UNIPD (0.802) & UNITO (0.703) \\
4 & UNIROMA1 (0.775) & UNIROMA1 (0.433) & UNIBA (0.565) & UNIPD (0.511) \\
5 & UNIPD (0.774) & UNIPD (0.365) & UNIROMA1 (0.550) & UNIVE (0.451) \\
6 & UNIPA (0.751) & POLITO (0.349) & UNIMIB (0.546) & UNIROMA1 (0.445) \\
7 & UNICT (0.742) & UNIMI (0.329) & UNIFI (0.537) & UNIMI (0.429) \\
8 & UNIMI (0.739) & UNIMORE (0.290) & UNINT (0.468) & UNIMORE (0.407) \\
9 & UNICH (0.684) & UNIVE (0.288) & UNICH (0.458) & UNIMIB (0.396) \\
10 & UNIPR (0.678) & UNIMIB (0.264) & UNINA (0.449) & POLITO (0.350) \\
\hline
\end{tabular}

\section{University network position}

Network centrality measures are considered to discover the most relevant universities in sending or attracting students. Hub and authority scores (Kleinberg, 1999) are chosen as the more informative ones in presence of directed and valued network data, since they point to in or out roles played by universities in the mobility network (Doreian and Mrvar, 2020; Soldano et al. 2017). Following Kleinberg's definition, a university is a good hub, i.e., good exporter, when it points to many good authorities, otherwise a university is a good authority, i.e., good importer, if it is pointed to good hubs. It is of interest to distinguish between these two complementary roles. In line with related research literature (Pitoski et al. 2021; Restaino et al., 2020; Urbinati et al., 2019), these scores allow to identify the set of universities which hold a privileged position. The hub score can be interpreted as an indicator of the awareness of student mobility choices in directing students to important universities, while the authority score is considered as an indicator of the attractiveness of a given university Both measures allow to rank the units of analysis by identifying the best exporters and importers.

From Table 3, we note that the exchange of students at a master's degree is driven by some leading Italian universities located mainly in the centre and north of Italy, such as UNIBO, UNICATT and UNIROMA1. Regarding the hub role, some universities in the south and centre of Italy emerge, such as UNIBA, UNIPA, UNIROMA1 and UNIFI, while the universities attracting students are mainly located in the north, such as UNIBO, UNICATT, UNITO, UNIPD and UNIVE.

Figure 4 compare hub and authority scores of the universities for the two cohorts showing geographical macro-areas aggregation. We note the prevalence of southern universities (green points) with high hub scores and northern ones (blue points) with high authority scores. For both cohorts the University of Bologna presents the highest hub and authority scores and most of southern universities are concentrated toward the origin of the axes. By comparing the two cohorts, other universities emerge in attracting students in 2014, and the Universities of Milan and Padua are also good hubs. The results show a medium-high correlation between the hub and authority universities (around 0.60 for both years). In particular, we are able to identify a set of universities that occupy a privileged position in the student mobility network, being both central authorities and important hubs, since they are able to attract students and, at the same time, to 


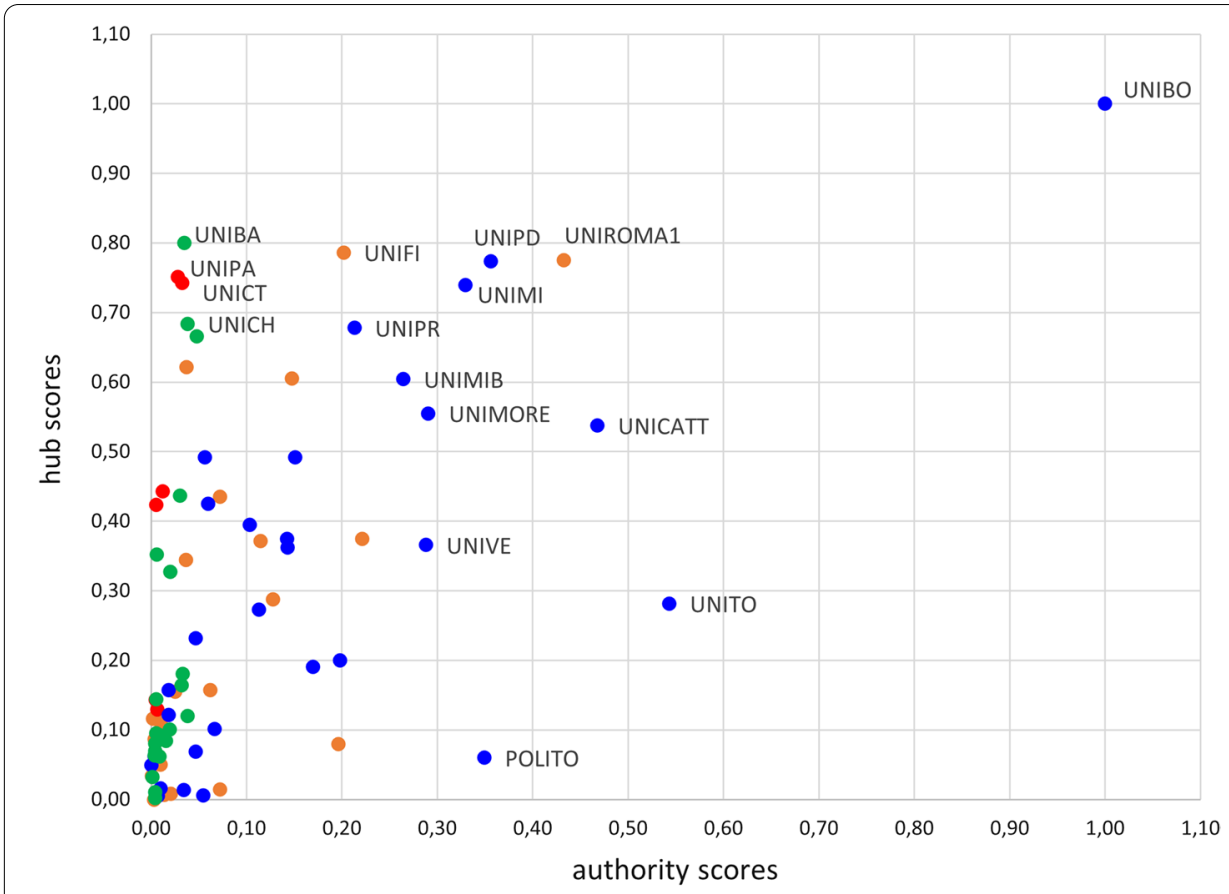

(a) 2011

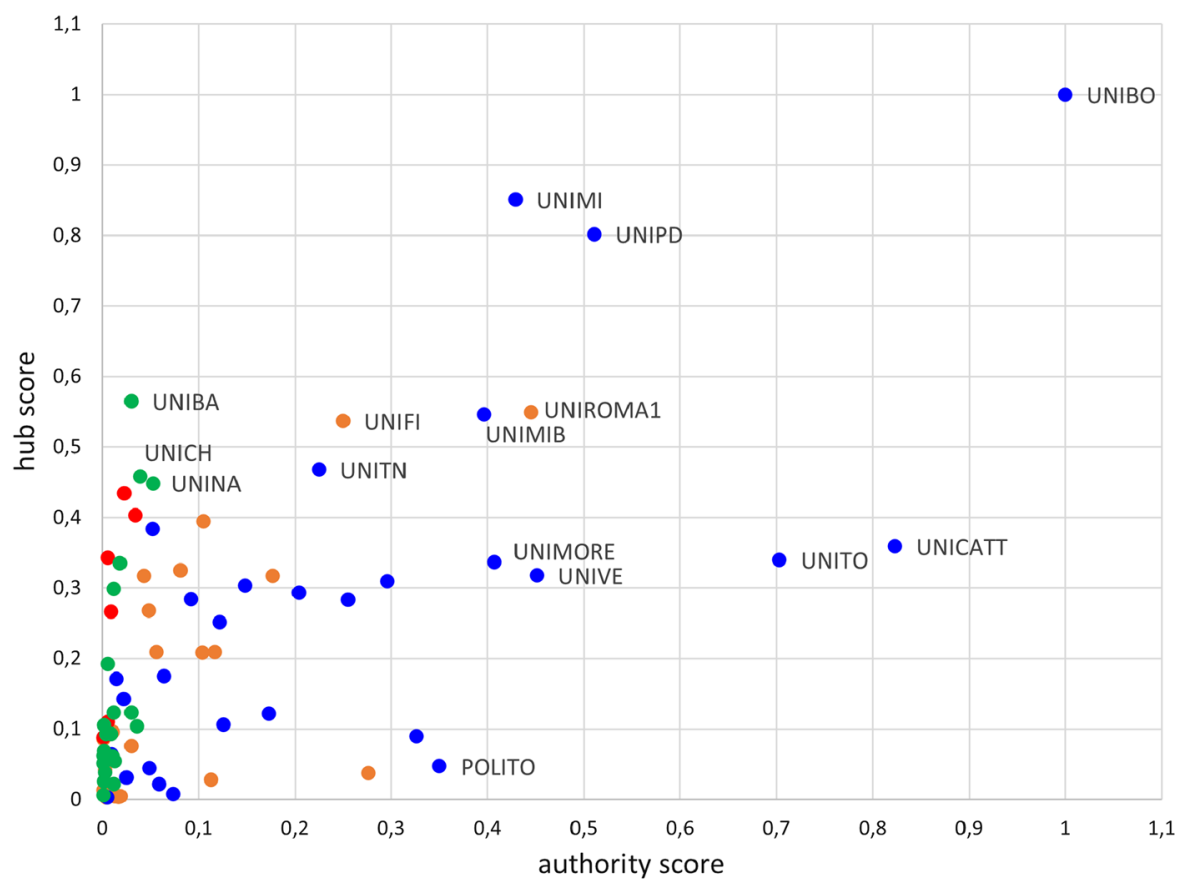

(b) 2014

Fig. 4 Scatterplots of hub and authority scores at university level of the 2011-12 and 2014-15 student cohorts according to the Italian macro-areas (blue $=$ north, orange $=$ centre, green $=$ south and red $=$ islands) 
provide entry to students for the most prestigious universities. Moreover, the majority of these universities shares similar patterns to their local neighbourhood.

\section{Modelling approach}

A logistic model has been estimated to study the probability for undergraduate students to be in mobility during their master's degree given that they have been stayer during their bachelor's degree and considering differences in students' characteristics and in the choice of the field of study. The analysis involved the subset of students who were Stayer I \& II (Profile 1) and Stayer I \& Mover II (Profile 3), with the aim to inspect the main factors which influence the probability to experience Profile 3 instead of 1 .

The coefficients estimated for the two cohorts are listed in Table 4. Findings provide evidence of a high level of agreement between the behaviour observed in the two cohorts in terms of the effect of determinants. There is a weak gender effect which signals a higher propensity for boys to the be in mobility in the transition from bachelor's to master's compared to girls. It is also confirmed the usual north-south divide with a higher share of second-level movers among those students who come from the south and the islands compared to those residing in the north, with an increasing size for students from south between the two cohorts. The model results suggest that the final grade obtained from students at the end of their bachelor studies acts as a push factor towards master's degree mobility choices.

Overall, results confirm the main findings which arise from the inspection of the distribution of students in the mobility categories displayed and discussed in "Data". The introduction in the model of network centrality measures linked to the universities of origin (hub centrality scores) and destination (authority centrality scores) provide evidence of the role played by the positions of bachelor's and master's universities of each student in the transition network. Namely, the master's degree authority centrality measures have been linked to the information concerning the university selected for master's degree studies (or university of destination), whereas the master's degree hub centrality measures have been linked to the individual information concerning the bachelor's degree university. The two network centrality measures have both positive signs with a different size which signal the stronger effect of the hub position of the origin university in determining the final probability to be in mobility at the second level. However, the negative sign and the size of their interaction terms show that the final effect is determined by the combination of both hub and authority positions of the origin and destination universities, in the student's exchange network. The negative interaction terms, in turn, suggest that the flows of students in mobility for the first time in the transition from bachelor's to master's is concentrated towards few universities which are good hubs and authorities at the same time with respect to the field of study they offer. Students who are in mobility in the transition are mainly attracted by universities with a good reputation and in this process a key role is played by the hub score of the origin universities, which highlight that these flows are driven by the information available on the reputation of master's programmes. Thus, the size and the sign of the hub scores and of the bachelor's degree grade suggest that flows of outgoing movers are composed by motivated and well-informed students, who look for better education opportunities in more prestigious universities. 
Table 4 Logistic parameters estimates (SDs in brachets)

\begin{tabular}{|c|c|c|}
\hline Predictors & 2011 Cohort & 2014 Cohort \\
\hline \multirow[t]{2}{*}{ Intercept } & $-7.029^{* * *}$ & $-7.015^{* * *}$ \\
\hline & $(0.208)$ & $(0.219)$ \\
\hline \multirow[t]{2}{*}{ Gender (M vs. F) } & $0.0625^{* *}$ & 0.0263 \\
\hline & $(0.0298)$ & $(0.0297)$ \\
\hline \multicolumn{3}{|l|}{ Macro area res (vs. NORTH) } \\
\hline \multirow[t]{2}{*}{ Center } & $1.091^{* * *}$ & $1.370^{* * *}$ \\
\hline & $(0.0408)$ & $(0.0389)$ \\
\hline \multirow[t]{2}{*}{ Islands } & $2.993^{* * *}$ & $2.966^{* * *}$ \\
\hline & $(0.0507)$ & $(0.0528)$ \\
\hline \multirow[t]{2}{*}{ South } & $2.580^{* * *}$ & $2.754^{* * *}$ \\
\hline & $(0.0428)$ & $(0.0442)$ \\
\hline \multicolumn{3}{|l|}{ High school (vs. Lyceum Hum.) } \\
\hline \multirow[t]{2}{*}{ Scient. } & $-0.0844^{* *}$ & $-0.115^{* * *}$ \\
\hline & $(0.0381)$ & $(0.0396)$ \\
\hline \multirow[t]{2}{*}{ Other } & $-0.146^{* * *}$ & $-0.0919^{* *}$ \\
\hline & $(0.0410)$ & $(0.0411)$ \\
\hline \multirow[t]{2}{*}{ High school grade } & $-0.00997^{* * *}$ & $-0.0101^{* * *}$ \\
\hline & $(0.00138)$ & $(0.00143)$ \\
\hline \multirow[t]{2}{*}{ Bachelor's degree grade } & $0.0311^{* * *}$ & $0.0270^{* * *}$ \\
\hline & $(0.00213)$ & $(0.00224)$ \\
\hline \multicolumn{3}{|l|}{ Disciplinary fields (vs. Social Sciences) } \\
\hline \multirow[t]{2}{*}{ Health and welfare } & $-0.638^{* * *}$ & $-0.468^{* * *}$ \\
\hline & $(0.0947)$ & $(0.0898)$ \\
\hline \multirow[t]{2}{*}{ Education } & $-0.633^{* * *}$ & $-0.703^{* * *}$ \\
\hline & $(0.0872)$ & $(0.0841)$ \\
\hline \multirow[t]{2}{*}{ Agri, for, fish and vet } & $-0.503^{* * *}$ & $-0.401^{* * *}$ \\
\hline & $(0.0947)$ & $(0.0884)$ \\
\hline \multirow[t]{2}{*}{$\mathrm{ICT}$} & $-0.480^{* * *}$ & $-0.312^{* *}$ \\
\hline & $(0.146)$ & $(0.125)$ \\
\hline \multirow[t]{2}{*}{ Arts and humanities } & $-0.371^{* * *}$ & $-0.329^{* * *}$ \\
\hline & $(0.0451)$ & $(0.0447)$ \\
\hline \multirow[t]{2}{*}{ Sciences } & $-0.303^{* * *}$ & -0.0300 \\
\hline & $(0.0489)$ & $(0.0481)$ \\
\hline \multirow[t]{2}{*}{ Services } & $-0.222^{*}$ & 0.140 \\
\hline & $(0.117)$ & $(0.108)$ \\
\hline \multirow[t]{2}{*}{ Eng and constr } & $-0.211^{* * *}$ & -0.00848 \\
\hline & $(0.0453)$ & $(0.0465)$ \\
\hline \multirow[t]{2}{*}{ Business, administration and law } & $-0.0720^{*}$ & $-0.164^{* * *}$ \\
\hline & $(0.0427)$ & $(0.0435)$ \\
\hline \multirow[t]{2}{*}{ Authority Destination University } & $1.155^{* * *}$ & $2.476^{* * *}$ \\
\hline & $(0.0790)$ & $(0.115)$ \\
\hline \multirow[t]{2}{*}{ Hub Origin University } & $8.760^{* * *}$ & $6.888^{* * *}$ \\
\hline & $(0.140)$ & $(0.104)$ \\
\hline \multirow[t]{2}{*}{ Authority $\times$ Hub } & $-7.164^{* * *}$ & $-6.865^{* * *}$ \\
\hline & $(0.188)$ & $(0.204)$ \\
\hline
\end{tabular}




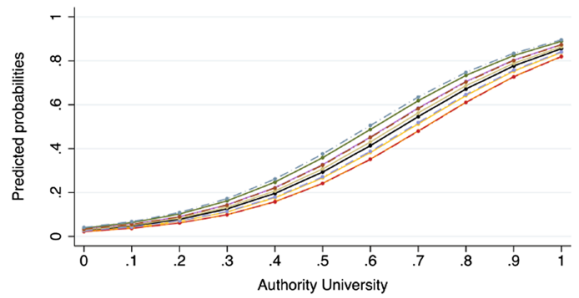

(a) 2011 Cohort

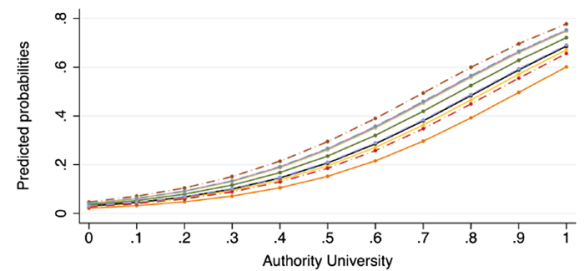

(c) 2014 Cohort

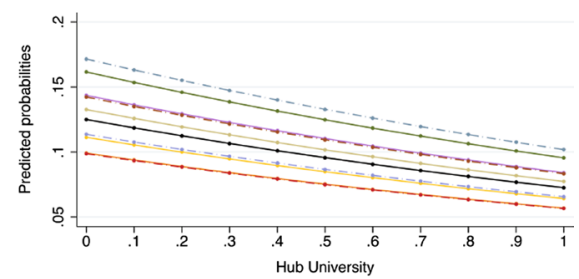

(b) 2011 Cohort

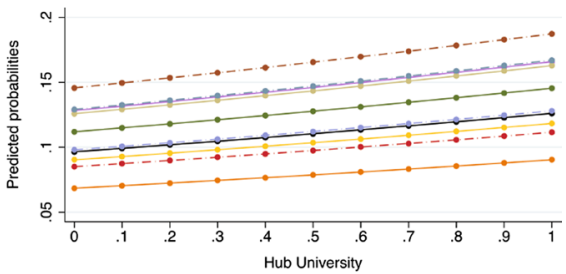

(d) 2014 Cohort

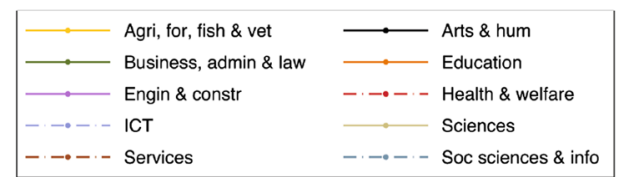

Fig. 5 Marginal predicted probabilities for the 10 disciplinary fields along with authority (a and $\mathbf{c}$ ) and hub (b and $\mathbf{d}$ ) measures. In the calculation of predictions, the remaining variables of the logit model are controlled to their mean value

Moving forward to the details regarding different fields of study, the model confirms that social sciences, journalism and information is the most attractive for students who decide to move for their master's studies. This result appears stronger in the 2011-12 cohort, while in 2014-15 cohort there is no relevant difference in the comparison with the field of natural sciences, mathematics and statistics, engineering, manufacturing and construction and services. Whereas education and health and welfare are the fields in which is more likely for students to make a choice of continuity for the higher level of studies. In Fig. 5 the differences by field of study in the predicted probabilities of being in mobility for the first time in the transition to the master are shown along the values of hub and authority scores. In the predictions the values of the remaining variables are controlled to their mean. Both, in 2011-12 and 2014-15 cohorts, the predicted probabilities are increasing for universities which are good importers (see Fig. 5a, c), while when looking at the hub measures, the behaviour changes when moving from the 2011-12 to the 2014-15 cohort.

\section{Conclusions}

Student mobility for attending the university studies has been a topic of increased academic and public interest in Italy, both from research point of view and from the side of all university stakeholders. In this contribution, mobility profiles at bachelor's and master's degree levels were considered by critically examining micro-data from the Italian National Students Archive referring to the cohorts of freshmen in 2011 and 2014. 
Regarding student mobility, our analysis has provided relevant definitions of different student profiles. These profiles have been carefully built considering the status of being a mover or a stayer at the bachelor's and master's degree levels.

Starting from this classification on the basis of student mobility status and looking at the flow of incoming and outgoing students observed between different universities, network centrality measures were obtained to describe push and pull factors which drive student flows from a bachelor's to a master's level.

To our current knowledge, this has been the first major attempt in the Italian framework to analyse student mobility choices by considering the overall student mobility pattern, and thereby focusing on the transition from a bachelor's to a master's degree. In doing so, we have maintained that the relationships between universities in the student mobility network act as push and pull factors in driving these dynamics. Previous academic researches have mainly focused on the determinants of student mobility at a specific degree level, i.e., bachelor's or master's yet without fully considering overall student mobility history (Bacci and Bertaccini, 2021; Enea, 2018). It has been this research gap that this study has attempted at filling. Both elements of novelties have allowed us to better shape differences in the determinants of student mobility choices for those students who come from very different experiences. The overall mobility pattern is intrinsically linked to students characteristics and their previous education performance and experiences. Namely, when we looked at the profile Mover I \& II, we observed that good performance at a high school level is a push factor in addressing student mobility choices, whereas when we consider Stayer I \& Mover II, we observed a similar situation yet now in relation to bachelor's degree grades. Therefore, these findings suggest that a good performance in bachelor's degree is an incentive to invest in a more prestigious master's degree title. We could also observe how the effect of network centrality can be indeed relevant in the transition to the second level of university studies, especially for those students who migrate for the first time for their master's degree. Moreover, by focusing on the subset of students who were stayers at the first level, the use of network centrality measures in a logistic model has allowed us to further assess the determinants of the probability of making a mobility choice at a master's level. The results we obtained made it possible to critically evaluate the probability of belonging to Stayer I \& Mover II profile rather than Stayer I \& Stayer II, controlling the hub and authority measures associated with the various universities and the field of study of the chosen degree programme. This way, the effect of the predictors associated with the characteristics of the student, such as the type of high school attended, gender, age, area of residence, is in line with several other studies previously conducted in the literature. What appears to be relevant here is the effect of the predictor referred to the hub and authority of origin and destination universities, and how their combination has a relevant effect on the probability to be in mobility at the second level. Considering the hub centrality measures as an indicator for student preference in moving towards a more attractive/prestigious university, i.e., with a high attractiveness score, it becomes evident that students who received their bachelor's degree from universities that proved to be good exporters also have the tendency to have a higher propensity to make a mobility choice at a master's level.

This result highlights the fact that the flow of students in mobility for the first time in the transition from a bachelor's to a master's degree is fundamentally influenced by 
student information acquired regarding the reputation of the destination university. In this complex process, a key role is played by the university environment at the bachelor's degree level, as is shown by the sign of the size of the hub centrality measures of the origin university. Additional research data on the subject-such as in the form of ad hoc surveys conducted on students themselves as well as on other relevant university stakeholders - could be highly beneficial to supplement further studies in this intriguing and upcoming research field.

\section{Acknowledgements}

Not applicable.

\section{Authors' contributions}

SC: Theoretical background, Modelling approach. MP: Conclusions. IP: Network data definition. IS: Introduction, Theoretical background, Data. MPV: University network position. All authors read and approved the final manuscript.

Funding

Italian Ministerial Grant PRIN 2017 CUP: B78D19000180001. Recipient: Mariano Porcu.

\section{Availability of data and materials}

The micro-data at student level used for the analyses are available by the ANS archive only for the universities involved in the Italian Ministerial Grant PRIN 2017 CUP: B78D19000180001. The data analyzed are derived from the MOBYSU.IT database.

\section{Declarations}

\section{Competing interests}

Not applicable.

\section{Author details}

${ }^{1}$ Department of Mathematics and Computer Sciences, University of Cagliari, via Ospedale 72, 09123 Cagliari, Italy. ${ }^{2}$ Department of Political and Social Sciences, University of Cagliari, Cagliari, Italy. ${ }^{3}$ Department of Political and Social Studies, University of Salerno, Fisciano, Italy.

Received: 20 December 2020 Accepted: 11 November 2021

Published online: 04 December 2021

\section{References}

Attanasio, M., \& Enea, M. (2019). La mobilità degli studenti universitari nell'ultimo decennio in Italia. In G. De Santis, E. Pirani, \& M. Porcu (Eds.), Rapporto sulla popolazione (pp. 43-58). II Mulino, L'istruzione in Italia.

Bacci, S., \& Bertaccini, B. (2021). Assessment of the university reputation through the analysis of the student mobility. Social Indicator Research, 156, 363-388.

Ballarino, G., \& Panichella, O. (2021). Social origins, geographical mobility and occupational attainment in contemporary Italy. Genus, 77(3), 1-24

Barrioluengo, M.S., \& Flisi, S. (2017). Student mobility in tertiary education: institutional factors and regional attractiveness. Tech. rep.: Publications Office of the European Union

Becker, G. (1964). Human capital: a theoretical and empirical analysis with special reference to education. The University of Chicago Press.

Columbu, S., Porcu, M., Primerano, I., Sulis, I., \& Vitale, M. P. (2021). Geography of Italian student mobility: a network analysis approach. Socio-Economic Planning Sciences, 73, 100918.

Columbu, S., Porcu, M., \& Sulis, I. (2021). University choice and the attractiveness of the study area: insights on the differences amongst degree programmes in Italy based on generalised mixed-effect models. Socio-Economic Planning Sciences, 74, 100926

D’Agostino, A., Ghellini, G., \& Longobardi, S. (2019). Out-migration of university enrolment: the mobility behaviour of Italian students. International Journal of Manpower, 40(1), 56-72.

Donnelly, M., \& Gamsu, S. (2018). Home and away: social, ethnic and spatial inequalities in student mobility. Tech. rep., Project Report. The Sutton Trust

Doreian, P., \& Mrvar, A. (2020). Hubs and authorities in the Koch brothers network. Social Networks, 64, 148-157.

Dotti, N., Fratesi, U., Lenzi, C., \& Percoco, M. (2013). Local labour markets and the interregional mobility of Italian university students. Spatial Economic Analysis, 8(4), 443-468.

Dotti, N., Fratesi, U., Lenzi, C., \& Percoco, M. (2014). Local labour market conditions and the spatial mobility of science and technology university students: evidence from Italy. Review of Regional Research, 34, 119-137.

Enea, M. (2018). From South to North? Mobility of southern Italian students at the transition from the first to the second level university degree. In C. Perna, M. Pratesi, \& A. Ruiz-Gazen (Eds.), Studies in theoretical and applied statistics SIS 2016., Springer Proceedings in Mathematics and Statistics (Vol. 227, pp. 239-249). Springer. 
Fratesi, U., \& Percoco, M. (2014). Selective migration, regional growth and convergence: evidence from Italy. Regional Studies, 48(10), 1650-1668.

Genova, V. G., Tumminello, M., Enea, M., Aiello, F., \& Attanasio, M. (2019). Student mobility in higher education: Sicilian outflow network and chain migrations. Electronic Journal of Applied Statistical Analysis, 12(4), 774-800.

Giambona, F., Porcu, M., \& Sulis, I. (2017). Students mobility: assessing the determinants of attractiveness across competing territorial areas. Social Indicator Research, 133(3), 1105-1132.

Istat. (2018). II benessere equo e sostenibile in Italia. Istituto Nazionale di Statistica: Tech. rep.

Kleinberg, J. M. (1999). Authoritative sources in a hyperlinked environment. Journal of the ACM, 46(5), 604-632.

Mencarini, L. (1996). Internal migration in Italy: an overview of studies in the early 1990s. Genus, 52(3-4), 173-188.

Pitoski, D., Lampoltshammer, T. J., \& Parycek, P. (2021). Network analysis of internal migration in Croatia. Computational Social Networks, 8(1), 1-17.

Pitzalis, M., \& Porcu, M. (2015). Passaggio a Nord. come si ristruttura il campo universitario Italiano? Scuola Democratica, 3, 711-722.

Primerano, I., Santelli, F., \& Usala, C. (2021). A multiplex network approach to studt italian students' mobility. In C. Perna, N. Salvati, F. Schirippa Spagnolo (Eds.), Book of short Papers SIS 2021, pp 473-478

Restaino, M., Vitale, M., \& Primerano, I. (2020). Analysing international student mobility flows in higher education: a comparative study on European countries. Social Indicator Research, 149(3), 947-965.

Rizzi, L., Grassetti, L., \& Attanasio, M. (2021). Moving from north to north: how are the students' university flows? Genus, $77(1), 1-22$.

Santelli, F., Scolorato, C., \& Ragozini, G. (2019). On the determinants of students mobility in an interregional perspective: a focus on Campania region. Journal of Applied Statistics, 31(1), 119-142.

Schultz, T. (1961). Investment in human capital. The American Economic Review, 51(1), 1-17.

Soldano, H., Santini, G., Bouthinon, D., \& Lazega, E. (2017). Hub-authority cores and attributed directed network mining. In 2017 IEEE 29th International Conference on Tools with Artificial Intelligence (ICTAI), IEEE, pp 1120-1127

Sulis, I., Columbu, S., Carta, A., \& Aru, P. (2019). La mobilità degli studenti universitari sardi. Un'analisi comparativa della domanda e dell'offerta di istruzione universitaria in Sardegna. Tech. rep.

Urbinati, A., Galimberti, E., \& Ruffo, G. (2021). Measuring scientific brain drain with hubs and authorities: A dual perspective. Online Social Networks and Media, 26, 100176.

VanMol, C., Caarls, K., \& Souto-Otero, M. (2020). International student mobility and labour market outcomes: an investigation of the role of level of study, type of mobility, and international prestige hierarchies. Higher Education. https:// doi.org/10.1007/s10734-020-00532-3.

Vitale, M., Giordano, G., \& Ragozini, G. (2020). University student mobility flows and related network data structure. In A. Pollice, N. Salvati, F. Schirippa Spagnolo (Eds.), Book of short Papers SIS 2020, pp 515-520

Vittorietti, M., Giambalvo, O., \& Aiello, F. (2019). A mobility analysis of the occupational status of the graduates of the university of Palermo in an economic crisis context. Electronic Journal of Applied Statistical Analysis, 12(4), 846-869.

\section{Publisher's Note}

Springer Nature remains neutral with regard to jurisdictional claims in published maps and institutional affiliations.

\section{Submit your manuscript to a SpringerOpen ${ }^{\circ}$ journal and benefit from:}

- Convenient online submission

- Rigorous peer review

- Open access: articles freely available online

- High visibility within the field

- Retaining the copyright to your article

Submit your next manuscript at $\boldsymbol{\Delta}$ springeropen.com 